\title{
La teoría del símbolo de Norbert Elias y su aplicación a la Historia del Arte
}

César García Álvarez

RESUMEN. Se analizan en este artículo las bases críticas de la posible aplicación de la teoría del símbolo defendida por el historiador y sociólogo de la cultura Norbert Elias, circunscrita en un principio al ámbito de los símbolos lingüísticos, a la teoría del arte, y en especial al problemático campo de la interpretación simbólica de las imágenes. Palabras clave: Teoría del símbolo, teoría del arte, sociología, Norbert Elias

ABSTRACT. The critical bases of the possible application of the Symbol Theory, supported by the historian and culture's sociologist Norbert Elias, to the Theory of Art, are analysed in this article. This theory was at first conceived for the study of linguistic symbols, but it can be applied to the Theory of Art, and specially to the problems of the symbolic interpretation of images.

Key words: Theory of symbol, Theory of Art, Sociology, Norbert Elias.

La última obra del historiador y sociólogo Norbert Elias (1897-1990) permite reflexionar acerca de la pertinencia de sus concepciones teóricas sobre la naturaleza del símbolo para el problema de la interpretación simbólica de las imágenes. El libro del historiador polaco ejemplifica perfectamente, al mismo tiempo, algunos de los desencuentros y malentendidos que se producen al utilizar un mismo término, como es símbolo, en disciplinas diversas del campo de las Ciencias Humanas y el estudio de la Historia del Arte.

A pesar de que la obra que aquí analizamos quedó inconclusa a la muerte del autor ${ }^{1}$, quien preparaba una introducción

\footnotetext{
${ }^{1}$ Véase el análisis introductor de Richard KILMINSTER a la obra de Elias, Teoría del símbolo. Un ensayo
}

que la completaría, la parte del texto acabada posee un carácter autónomo y autosuficiente que permite extraer de ella abundantes elementos para la reflexión teórica.

La obra de Elias plantea una comprensión del símbolo en la que se acentúan de manera especial las dimensiones sociológicas del mismo. El símbolo lingüístico, entendido como una pauta sonora dotada de significado por medio de un acuerdo convencional de un grupo social, es la noción que recorre y vertebra todo el discurso del autor. Elias rechaza así parte de la tradición filosófica occidental, centrada en un individualismo metafísico según el cual la posibilidad de hablar, y la creación de sig-

de antropología cultural, Barcelona, Península, 1994, pp. 7-25. 
nificado, parecerían ser una función y una prerrogativa exclusiva de individuos aislados. Según Elias, ni el conocimiento ni el lenguaje son posibles sin una sociedad que regule el funcionamiento y significado de las pautas sonoras, las palabras. Todo significado es social, y por tanto "lo que no está representado simbólicamente en el idioma de una comunidad lingüística no es conocido por sus miembros; no pueden comunicarse entre sí sobre ello" ${ }^{2}$. La centralidad del lenguaje como creador de símbolos, como condición de la creación de conocimiento, de su comunicación a otros seres humanos, le confiere una cierta autonomía respecto a cualquier hablante particular ${ }^{3}$. Los símbolos sonoros humanos no tienen un origen absoluto en un momento del tiempo, sino que son consecuencia de un proceso de desarrollo ininterrumpido de perfeccionamiento y sofisticación de la función lingüística, igualmente presente, en menor grado, en los animales. El conjunto

\footnotetext{
${ }^{2}$ N. ELIAS, Teoría..., p. 35.

${ }^{3}$ Ibídem, p. 58. Aunque no es el objetivo de este artículo, no deben ignorarse las implicaciones que el antiindividualismo de Elias posee para la teoría del conocimiento. En este sentido, la postura de Elias es reduccionista, puesto que otros marcos teóricos, como la Hermenéutica, si bien reconocen que la formación de cada individuo exige el conocimiento de lo ya dado y presente en la sociedad, en este caso el idioma, pero también las costumbres y las instituciones, al mismo tiempo perciben este acto de exteriorización del individuo como la primera parte, incompleta, del proceso formativo. Para ser íntegro, éste requiere un retorno a sí después de la enajenación. Es decir, que la dialéctica del sentido entre la sociedad y el individuo no permite eliminar ninguno de los dos términos, lo cual implica que el individuo es también portador y creador de sentido (cfr. H. G. GADAMER, Verdad y método, Salamanca, Editorial Sígueme, 1977, p. 43). De este modo se aprecia que Elias considera la dimensión social del lenguaje no sólo suficiente y necesaria, sino autosuficiente. Esta parcialidad es congruente, como veremos, con la escasa atención prestada en su libro a las funciones no denotativas del lenguaje, y quizá explique su falta de atención al arte, cuyas creaciones rebosan lo denotativo para incluir lo connotativo, expresivo y no racional
}

de símbolos sonoros, el lenguaje, permite al hombre habitar una quinta dimensión, simbólica, que abarca y modifica las otras dimensiones espacio-temporales ${ }^{4}$. Al igual que Cassirer, Elias considera la función simbólica como la distintiva y constitutiva del ser humano. La sociedad es una red de hablantes que precisa del lenguaje para conocer y comunicar.

De este modo, la naturaleza del símbolo lingüístico radica precisamente en carecer de ella. Las palabras sólo tienen significado si un grupo social lo establece y lo transmite a cada uno de sus miembros. No es extraño que Elias rehuya y rechace el problema de los orígenes del lenguaje, porque si el significado de una palabra se recibe de un grupo social que antes lo ha fijado, se plantea la condición paradójica de que tal significado ya existía, por principio, antes de que ningún hablante individual lo aprendiese, y por tanto la invención de palabras o de significados nuevos resultaría imposible. Por otra parte, para Elias el significado de una palabra parece ser siempre expresado mediante otras palabras, y por tanto lo que el lenguaje no puede hacer explícito no pertenece al significado de las palabras. Se añade la dificultad de que el autor no explica el procedimiento por el que las palabras nuevas pasan a estar dotadas de significado, ni por el que palabras viejas pasan a poseer significados nuevos. La idea de significado pasa a ser idéntica a la de significado consciente y establecido socialmente.

Este es otro de los reduccionismos de los que, sin embargo, Elias declara explícitamente querer huir a toda costa. Tomemos como ejemplo la palabra abracadabra, que el autor utiliza para demostrar que "no es una palabra, porque no lleva el sello de un grupo humano que la haga entendible para

\footnotetext{
${ }^{4}$ N. ELIAS, op. cit., p. 90.
} 
todos sus miembros como símbolo de una función y objeto específicos. Es un sonido sin significado ${ }^{5 "}$. Esto es un error por partida doble. En primer lugar, abracadabra poseyó un significado concreto para determinados grupos gnósticos y esotéricos cuyo significado proviene al parecer de una deformación del hebreo pronunciada como "abreg ad hâbra", es decir, "envía tu rayo hacia la muerte ${ }^{6 "}$. Por tanto, para algún grupo social, abracadabra fue una pauta sonora dotada de significado preciso, y por tanto una palabra, un símbolo. Pero es que, además, el significado de abracadabra no se limita a informar a otros hablantes de la existencia de una realidad concreta o abstracta, sino que, como fórmula mágica que ha sido, trata de provocar en el oyente una sensación de misterio o extrañeza, que garantiza que la manifestación de una fuerza sobrenatural a la que se invoca va a producirse. Parte de la carga de significado de abracadabra es, por un lado, emocional, y por otro, vaga e imprecisa, la oscuridad incomunicable y difusa de lo numinoso. Incluso, tras la momentánea derrota del pensamiento mágico por la racionalidad cientifista, significa la referencia cómica e irónica a la ineficacia e inutilidad de toda palabra ritual, de toda fórmula mágica. De modo que abracadabra sí es una palabra, pero parte de su función semántica reside, precisamente, en desbordar la capacidad racional de quien la lea u oiga, amendrentándole ante la cercanía de lo irracional. La palabra cumple su efecto, y transporta significados, incluso si los hablantes o receptores desconocen el significado etimológico o la significación concreta determinada $\mathrm{o}$ acordada por un grupo. Es cierto que la comprensión de su sentido requiere en todos los casos un proceso social de asignación de significado, pero éste no es concreto

\footnotetext{
${ }^{5}$ Ibídem, p. 96.

${ }^{6}$ J. Chevalier, y A Gheerbrant, Diccionario de símbolos, Barcelona, Editorial Herder, 1986, p. 44.
}

ni preciso, como supone Elias que es preceptivo para la formación del significado de las palabras. Abracadabra ha pasado a ser una palabra sin significación concreta, pero cuya pronunciación constela alrededor suyo todo un campo de significados implícitos, de connotaciones mágicas, de asociaciones inconscientes. Toda palabra oculta bajo su superficie un campo rico y no necesariamente desordenado de implicaciones y connotaciones, que excede a la dimensión y función superficial de su significado denotativo. Las palabras evocan, provocan estados de ánimo, reacciones psíquicas complejas, que en su mayor parte resultan intraducibles a otras palabras.

El ejemplo precedente muestra alguna de las limitaciones de la teoría de Elias. El autor ignora, consciente o inconscientemente, la amplia variedad de funciones que las palabras pueden desempeñar, y que no se limitan a las tres funciones que diferencia de los símbolos como medios de orientación al servicio del conocimiento, de lenguaje al servicio de la comunicación, o de investigación al servicio del pensamiento ${ }^{7}$. Quizá el problema sea solamente terminológico ya que, al igual que ocurre en obras de teóricos de la semiótica, como Peirce o Morris, el término símbolo se utiliza en un sentido distinto al que las tradiciones filosóficas occidentales anteriores al siglo $X X$ habían establecido. En efecto, Elias afirma categóricamente que "el símbolo puede percibirse literariamente como una imagen o una pintura de aquello a lo que representa. Sin embargo, en la mayoría de los casos, en todos salvo en aquellos en los que están representados simbólicamente los propios símbolos, los símbolos son totalmente distintos de lo que simbolizan" ${ }^{8 \prime}$. Quizá resida en este pasaje la clave de los malentendidos a los que antes aludíamos. La idea tradicio-

\footnotetext{
${ }^{7}$ N. ELIAS, op. cit. , p. 122.

${ }^{8}$ Ibídem. p. 172.
} 
nal de símbolo, presente la tradición platónica y hegeliana, así como en todas las disciplinas de la Simbólica Tradicional, y en la Hermenéutica, entre otras tradiciones culturales, se define como una relación necesaria entre el significante y el significado simbolizado. Las relaciones convencionales, no motivadas, no son símbolos, sino signos, éstos sí convencionales y arbitrarios. Sin embargo, Elias aborda la función denotativa de las palabras como pautas sonoras establecidas arbitraria y convencionalmente, y las denomina símbolos, invitando a la confusión a quienes conozcan la tradición interpretativa de la palabra a la que nos acabamos de referir. La teoría del símbolo de Elias es, más bien, una teoría del lenguaje, o mejor aún, de las palabras como pautas sonoras que transmiten significados precisos.

Aquí radica otro punto de posible confusión. $Y$ es que la definición tradicional de símbolo lo entiende también como la representación de una realidad en sí misma incognoscible, que sólo puede ser percibida parcialmente por medio del propio símbo$10^{9}$. El significado simbólico desborda al significante, y es paradójico, puesto que el símbolo es al mismo tiempo congruente e incongruente con respecto al significado. El símbolo se adentra siempre en lo metafísico, en lo supra o infra-racional, alude a realidades inabarcables mediante la razón, y

\footnotetext{
${ }^{9}$ La definición de Jung del símbolo como "la imagen de un contenido en su mayor parte trascendente a la consciencia" (C. G. JUNG, Símbolos de transformación, Barcelona, Paidós, 1993, p. 102) y la atribuida a Jung por J. M. G. ESTOQUERA, “La mejor formulación posible de una realidad desconocida", en "Símbolo", en A. ORTIZ-OsÉs, (coordinador): Diccionario de Hermenéutica, Bilbao, Universidad de Deusto, 1997, p. 757, resume bien esta concepción esotérica de lo simbólico como la relación no racional, sino analógica, entre significantes y significados fundamentalmente metafísicos, De la misma opinión son J. E. CIRLOT, Diccionario de símbolos, Barcelona, Labor, 1982, pp. 15-18, y J. CHEvalieR, y A. GHEERBRANT, Diccionario..., pp. 18 y ss.
}

por tanto, difícilmente comunicables a un grupo social. No en vano, el conocimiento del significado profundo de los símbolos ha exigido en numerosos momentos de la Historia el requisito de una iniciación, imprescindible para alcanzar la comunión con el símbolo y la realidad simbolizada. Elias no trata estas cuestiones. Simplemente se limita a teorizar sobre la función simbólica de las palabras, sin sobrepasar en realidad su función denotativa de conceptos traducibles a otras palabras, y sin abordar otras funciones posibles y reales, tanto de las palabras como de las imágenes.

En efecto, el autor escribe acerca del papel de las imágenes mnemotécnicas almacenadas en la mente como una de las posibles fuentes creadoras y movilizadoras de símbolos para la reflexión y el pensamiento, y afirma también que "la capacidad imaginativa es el padre y la madre del arte, y aún indispensable para la supervivencia de la humanidad" ${ }^{10}$. Pero no va más allá de estas consideraciones, y nos priva de una explicación más detallada de las relaciones entre imaginación, palabra e imagen artística. La teoría de Elias no aborda en absoluto el problema de las imágenes como símbolos, de la posibilidad de que las formas icónicas sean capaces de poseer, transmitir y fijar significaciones simbólicas.

En realidad, éste es uno de los problemas centrales de cualquier teoría de la imagen simbólica. Las imágenes no son palabras, pese a los muchos esfuerzos dedicados a identificar totalmente arte y lenguaje, pero entre imágenes y palabras se pueden establecer unas relaciones fructíferas, e incluso imprescindibles. Las imágenes no están formadas por palabras, sino por materia estructurada y perceptible estéticamente, por los sentidos y la mente ${ }^{11}$. La

\footnotetext{
${ }^{10}$ N. ELIAS, op. cit, p. 123.

${ }^{11}$ Un problema distinto y complementario, que aquí no podemos abordar, es el de la utilización de la
} 
naturaleza de la imagen desborda las posibilidades de la palabra. Toda imagen puede generar un número en principio ilimitado de interpretaciones, de discursos traducibles a palabras, pero su condición primera no es la de ser lenguaje, aunque pueda generarlo. Una imagen, si usamos la terminología de Elias, sí puede considerase como una pauta, no sonora, sino icónica. Pero como tal pauta icónica, plástica, puede ser relacionada con un número a priori no limitable de pautas sonoras. Cada palabra o conjunto de palabras que se pronuncia sobre una imagen contiene una interpretación explícita o implícita de la misma, y la multiplicidad de discursos posibles delata la naturaleza parcialmente abierta e inestable de las formas icónicas, indefensas en ocasiones ante posibles interpretaciones erróneas. Sin embargo, a pesar del riesgo de asignar a las imágenes palabras inadecuadas a su verdadero sentido, el concurso de las palabras es imprescindible si se desea hacer explícitos y poder comunicar tales significados.

Por otra parte, determinadas imágenes son o pueden ser consideradas como símbolos. Afirmar que el círculo es símbolo de eternidad, plenitud, del tiempo o del sí mismo, que el pelícano es símbolo de Jesucristo, o una columna símbolo de la fortaleza, implica reconocer en determinadas imágenes la capacidad de ser significantes de determinados conceptos. En estos casos, las imágenes son símbolos en el sentido tradicional del término, porque comparten con lo simbolizado algunas características comunes. La columna es fuerte, el pelícano alimenta con su sangre a sus crías como Cristo alimenta a sus fieles, y el círculo carece de principio y fin, es completo e

palabra como materia de la obra de arte, es decir, la consideración como arte de la literatura en todas sus formas, y al mismo tiempo la presencia de palabras escritas como parte integrante de obras plásticas. ilimitado, regular y perfecto. Cualquier columna figurada (pintada, esculpida, fotografiada, filmada) puede ser entendida, una vez entendida esta relación, como símbolo de la fortaleza, pero, y aquí es posible engarzar con la teoría de Elias, para que su significado se vuelva explícito, es imprescindible el concurso de un nombre, de una palabra. No es la totalidad de la columna pintada, con su realidad plástica plena y con todas sus variaciones formales y estilísticas posibles, la que permite afirmar que "la columna simboliza la fortaleza", sino la aplicación de la pauta sonora "columna" a una forma, y la percepción, o el acuerdo, de que tal aplicación resulta apropiada, que lo descrito como "columna" es una columna y no un percebe o cualquier otra realidad.

Las palabras son los puentes que permiten cruzar desde el terreno de lo material y formal al terreno de lo semántico, explícito y dotado de una dimensión social. Como Elias se preocupa ante todo de la función denotativa e informativa del símbolo lingüístico, no parece percibir que los símbolos no verbales, las imágenes, exceden los límites, a veces muy estrechos, de la razón, el lenguaje y los conceptos. Ello no impide reconocer que, para hablar de las imágenes, son imprescindibles los conceptos y su reflejo, las palabras. No se puede hablar de las imágenes sin utilizar pautas sonoras, o mímicas, en el caso del lenguaje de los sordomudos. Pero pueden existir acercamientos a las formas sin el concurso del lenguaje, y los conceptos no son más que una parte posible, necesaria incluso, aunque no suficiente, de la experiencia estética, que sin el concurso de las palabras permanece latente cerca o debajo (o incluso por encima) del umbral de la consciencia y el proceso de pensamiento de cada cual, pero no puede ser comunicada a otros. Claro que, siguiendo a Wittgenstein, a lo mejor es preferible callar. 
Aunque Elias no concibió su teoría del símbolo para la interpretación de las imágenes, hemos visto que sí puede tener cabida en el complejo universo teórico de la interpretación de las obras de arte. A este respecto, quizá pueda resultar útil la idea defendida por Elias de que el conocimiento de la realidad es perfectible. Así, tras la palabra sol se escondía en la Antigüedad una amalgama de creencias míticas y fantasías poco congruentes, según el autor, con la realidad científica, que nos permite en el siglo XX pronunciar la misma palabra sol que los antiguos y ver en ella una masa de helio en fusión nuclear en vez de el ojo divino que da vida a lo existente, el padre de fuego de los cielos ${ }^{12}$. Pese a la convicción de Elias, es bastante dudoso que cada vez que hoy día alguien mira al sol piense en la definición científica, pero no cabe poner en duda que el conocimiento sobre el sol ha aumentado. Del mismo modo, el conocimiento del significado de las imágenes puede igualmente ampliarse. Ejemplo de ello han sido, a lo largo del siglo XX, el surgimiento de marcos teóricos de interpretación de las obras de arte refinados y complejos, como el Psicoanálisis, la Iconología, y las versiones modernas de la Hermenéutica, la Psicología de la Percepción o la Semiótica, entre otras. Cada una de ellas, con un lenguaje específico, ha propuesto tipos de palabras concretos para interpretar las creaciones artísticas, y su aportación ha enriquecido nuestra percepción del arte y aumentado nuestro conocimiento.

La mejor manera de integrar estas aportaciones es considerarlas como desvelamientos de diferentes dimensiones de significado en principio independientes, pero armonizables en una síntesis superior. Esta idea de síntesis aparece en Elias como uno de los objetivos del conocimiento

\footnotetext{
${ }^{12}$ Sobre este simbolismo del sol, véase L. SCHNEIDER, Arte y psicoanálisis, Madrid, Cátedra, pp. 160-170.
}

humano $\mathrm{y}$, aunque no aplicada al conocimiento del arte como nosotros proponemos, resulta útil, estimable y deseable. Sobre todo, porque una obra de arte es una unidad formal y material, y resultaría paradójico que sus significaciones fuesen fragmentarias e inconciliables entre sí, lo que sin embargo sí sucede en ocasiones en el proceso de su interpretación.

Este último aspecto es uno de los problemas teóricos más espinosos ligados a la sociología del arte. Las posiciones de este modelo teórico oscilan entre el reconocimiento de significados permanentes, objetivos y estables en las imágenes, dotadas de una naturaleza semántica y simbólica precisa, y la negación de toda objetividad de su significado, en favor del papel de diferentes grupos sociales que proyectan sus intereses, objetivos y deseos en las imágenes, que reemplazan su objetividad por la subjetividad y libertad de uso de las formas por parte de los intérpretes ${ }^{13}$. La concepción por parte de Elias del conocimiento humano como el logro de síntesis cada vez más elevadas e integradas, unida a la idea que proponemos de la existencia de multidimensionalidad semántica en las formas icónicas, permitiría comprender las diferentes interpretaciones como fases dialécticas aparentemente contradictorias, pero en realidad armonizables en una síntesis más elevada que de momento sólo puede ser vislumbrada.

En esencia, cabe afirmar que las imágenes necesitan de las palabras para que sus significados se hagan explícitos y puedan ser comunicados. Cada palabra es una pauta sonora cuyo significado está más o menos regulado socialmente. Al proponer una relación entre una palabra y una forma icónica, dicha palabra aísla una propiedad

\footnotetext{
${ }^{13}$ Una completa síntesis de estos planteamientos sociológicos, en V. FURIó, Sociología del arte, Madrid, Cátedra, 2000.
} 
o dimensión de las formas icónicas y permite relacionarla con otras palabras, incrementando el conocimiento de las imágenes, y permitiendo armonizar las interpretaciones en síntesis cada vez más completas. Alguna de las ideas centrales de Elias, como son la del símbolo como pauta dotada de significado por convención social y la perfectibilidad del conocimiento de la realidad pueden ser aplicadas a una teoría de la imagen simbólica.
Otros muchos conceptos y aspectos interesantes hay en la teoría de Elias, pero consideramos que su relación con el problema de los símbolos en el arte es menos trascendente que los que hemos analizado. Con este artículo sólo pretendemos llamar la atención sobre los puntos de contacto existentes entre la teoría del símbolo de Elias y la teoría del símbolo tradicionalmente aplicada al arte, como esbozo de una deseable síntesis metodológica más amplia. 